\title{
The Quadrivium of Online Public Consultation: Policy, Culture, Resources, Technology
}

\author{
Jim Macnamara \\ University of Technology Sydney
}

\begin{abstract}
Concerned by declining interest, trust, and participation by citizens in democratic politics, governments and political institutions worldwide are turning to the internet in attempts to revitalise democracy through online public consultation and citizen participation, referred to as edemocracy or 'government 2.0'. This paper reports research into the planning and conduct of a series of online public consultation trials launched by the Australian federal government in late 2008, and compares and contrasts Australian experiences with international e-democracy developments including the Obama presidential campaign and findings of the Digital Dialogues review of online technologies to enhance citizen engagement in the UK, the UK Power of Information Task Force review, and experiments conducted as part of the MIT Deliberatorium. It presents qualitative analysis of findings in 10 areas which it argues can be further grouped into four main areas of management focus of which technology, often the major topic of discussion, is important but less significant than policy, culture and resources.
\end{abstract}

\section{Introduction}

Concerned by declining citizen engagement and participation in democratic politics (Dahlgren 2009, 1; McAllister 2002), declining citizen knowledge and interest in politics, and declining citizens' trust in politicians and representative institutions (Gibson, Lusoli and Ward 2008, 111-13), governments and social scientists have focussed increasing attention on the potential for online interaction via the internet to address this deficit and revitalise democracy. In particular, the emergence of interactive internet applications such as blogs, social networks, video sharing sites like YouTube, wikis, and microblogging as part of what is termed Web 2.0 has created a resurgence in interest in online engagement and participation.

The 2004 US presidential election campaign was described as 'a critical turning point for political communication via the internet' by Xenos and Moy (2007, 704). However, while they noted that '2004 marks the year in which online politics finally reached a "mainstream" audience', many of the most widely used Web 2.0 media today did not exist in 2004. YouTube was launched in 2005; Facebook opened to the public in September 2006; and Second Life and Twitter also launched in 2006. Therefore, ongoing review of online political communication is necessary.

A more contemporary gauge of the potential of online political communication was provided by the 2007 Australian federal election and even more particularly by the 2008 US presidential campaign. A study of the 2007 Australian federal election, widely described as the 'Google election' (Gibson and Ward 2008, 5) and 'the YouTube election', found such claims to be 'greatly exaggerated' (Macnamara 2008, 8). While internet reporting and discussion of the election outstripped press, radio and TV coverage in total (Goot 2008, 99), a study of use of interactive Web 2.0 media by major political actors found that only 26 of Australia's 226 incumbent politicians (11.5 per cent) had a MySpace site; just 15 (6.6 per cent) had a blog; only 13 (5.75 per cent) posted videos on YouTube; just eight (3.5 per cent) had a Facebook site; and only seven (3.1 per cent) podcast. Furthermore, it reported that most 
online media used by politicians and political parties either heavily moderated public comments, or turned off interactive features altogether. However, there was significant online citizen engagement in some independent blogs and activist group sites such as GetUp (www.getup.org.au); Election Tracker (www.electiontracker.net.au) which presented a youth perspective on political issues; and You Decide (http://youdecide2007.org) which invited citizens to report on issues in their electorates (Flew \& Wilson 2008; Macnamara 2008, 9).

The 2008 US presidential campaign brought interactive Web 2.0 media into heightened focus as channels through which to engage citizens, although much of the Obama campaign was aimed at fund-raising. Nevertheless, in terms of the Habermassian notion of the public sphere and deliberative democracy (Habermas 1989, 2006), as well as representative, republican and participatory models of democracy, there was evidence of significant online political engagement in the Obama campaign. In a Pew Internet and American Life Project study, Smith and Rainie reported that during the 2008 presidential campaign, 46 per cent of all Americans used the internet to access news about the campaign, share their views and mobilise others $(2008, \mathrm{i})$.

However, the processes of public consultation and citizen engagement in a democracy require political leaders, public servants and scholars to look beyond election campaigns to examine uses and effectiveness of interactive internet communications more broadly, and this area is receiving increasing focus.

\section{e-Government and e-Democracy}

Use of the internet for delivery of information and services as well as public consultation and citizen engagement have received increasing attention around the world since the mid-1990s and a number of terms such as e-government, open government, government 2.0, $e$ democracy, e-citizenship, digital democracy, teledemocracy and cyberdemocracy have entered the political lexicon. While some define e-government broadly encompassing all online contact between governments and citizens (e.g. Silcock 2001), this term has been used most widely in referring to the delivery of government information and services to citizens conceptualised as 'consumers' (ASPA and UNDPEPA 2002, 1; Hernon, Cullen and Relyea 2006). Studies show that electronic delivery of services has dominated governments' online agenda for the past decade (Geiselhart 2004; Dunleavy et al. 2008, 13). However, because of the perceived 'crisis in representative democracy' (Gibson et al. 2008, 113), there is increasing focus on using interactive internet applications for public consultation and citizen engagement, either as an extension of e-government or as a specific area of focus. For example, an OECD e-Government Studies report (OECD 2003a, 3) lists three elements of egovernment including 'e-consultation' and in an analysis of e-government in Australia Sue Burgess and Jan Houghton (2006, 84) cite three broad goals of e-government as 'citizen engagement, efficiency, and the effectiveness of service delivery'.

Others prefer to distinguish online service delivery from online public consultation and citizen engagement, referring to the latter as e-democracy which is defined by Ian Kearns as 'the use of Web technologies to engage citizens in debate, discussion, consultation and online voting' (2002, 11). This term was also used by the Department of Finance and Deregulation (2008) in Australia for its initiatives in online consultation discussed in this paper, although the Federal Government has subsequently adopted the term 'Government 2.0' for a taskforce set up to further investigate use of Web 2.0 technologies to expand public consultation and citizen engagement (Tanner and Ludwig 2009). 
The level of citizen engagement considered necessary or desirable varies in different models of democracy, as Peter Dahlgren (2009, p. 2) notes. While some categorise democracy as representational or direct, Jürgen Habermas (2006) contrasts three models: liberal, republican and deliberative. Liberal approaches privilege individual freedom, often involving voluntary voting, and gain citizens' views as informally gauged public opinion. What Habermas calls the republican model most closely aligns with what others call representative democracy and involves political engagement primarily through elected representatives. A deliberative approach, also discussed by David Held (2006), stresses the importance of active citizen engagement in thinking about political issues and expression of opinions (Habermas 2006, $411-3)$.

Within Western democracies public consultation has been quite specifically, and some say, narrowly conceptualised as discussion with and consideration of the views of key representative groups and major 'political actors' such as elected representatives, industry associations, trade unions, lobbyists, and journalists (Habermas 2006, 416). Habermas (1989, 2006) and Held (2006) argue that a deliberative form of democracy is preferable to or a necessary part of republican or representative models as it involves a substantial number of people which avoids representatives becoming a 'power elite' and it involves reflective thinking about issues by citizens. A key requirement for deliberative democracy, according to Habermas (1989), is a public sphere in which 'citizens come together and confer freely about matters of general interest' and engage in 'rational-critical debate' to become informed, contribute to political discourse, and reach consensus. Despite criticism for being a normative ideal, 'excessive emphasis on rationality' (Dahlgren 2009, 8), and elusiveness in its realisation, the concept of an active public sphere has remained an enduring notion in contemporary democratic societies. There is also recognition of the desirability and even necessity of citizen engagement and participation in representational and republican models of democracy (Dahlgren 2009, 15). As Rowe and Frewer note, there is 'a move away from an elitist model ... to one in which citizens have a voice' (2004, 513).

In its traditional form, consultation is mostly conducted in a prescribed formal or semi-formal manner, such as through written submissions, inquiries, hearings, reviews, and in meetings. In contrast, discussion in interactive online environments occurs in a dynamic, open and often colloquial conversational way (Scoble and Israel 2006). The interactions of Web 2.0 are located primarily in popular culture and have a more free-wheeling notion of consultation than largely elitist formal consultation processes. Brian McNair notes that the internet is a 'more crowded, noisy, chaotic, competitive, and rancorous communications space than was envisaged for the modernist public sphere' (cited in Flew 2008, 165). However, given the stated commitment of governments to engage in online public consultation using Web 2.0 communication applications, it is necessary to accept not only more open consultation, but also the more informal nature of online dialogue that characterises these applications.

\section{Analysis of Australian Online Consultation Trials}

Following its late 2007 election, the Rudd government tasked the Australian Government Information Management Office (AGIMO) to develop a detailed strategy for implementing online public consultation and participation and Consulting with Government - Online was released in June 2008 (AGIMO 2008). In July 2008 the Minister for Finance and Deregulation, Lindsay Tanner, announced the establishment of a trial government consultation blog to 'give the online citizenry a chance to interact with the bureaucracy and make contributions to an area of government policy review’ (Tanner 2008). 
The government subsequently launched three online consultation sites in December 2008: a public consultation blog hosted by the Department of Broadband, Communications and Digital Economy; the National Human Rights Online Consultation forum established by the Attorney-General's Department; and an online forum on early childhood education conducted by the Department of Education, Employment and Workplace Relations.

Researchers from the University of Technology Sydney conducted an independent study of the planning and conduct of the three online public consultation sites, as well as examining existing federal department and agency Web sites involved in online public consultation during the period August 2008 to March 2009. The study proceeded in three stages, although with e-democracy initiatives still in their relative infancy, this research is ongoing and should be viewed as an initial pilot study in this field. This research did not examine the experiences of participants in the online public consultation initiatives and it is acknowledged that this is an under-researched area, as noted by Gibson, Lusoli and Ward (2008) who conducted one of the very few studies of the 'demand side' on online public consultation in 2005. This is an important area for future research. Nevertheless, this 'supply side' study provides some interesting findings that inform future policy making and operationalisation of online public consultation and citizen engagement.

\section{Methodology}

While the study collected some quantitative data on site visitors and volume of postings, its primarily objective was to gain an understanding of the objectives, planning processes, operational experiences, perceptions and learnings of government departments and agencies involved. Therefore, qualitative research methods were used. In the first stage, the researchers conducted depth interviews with officials involved in planning and operationalising the three official online consultation trials, as well as existing sites involved in online public consultation and citizen engagement, combined with qualitative content analysis of relevant sites.

Given that the study's objectives were to study active federal government online consultation and citizen engagement projects, purposive sampling was used initially to select the three online consultation trial sites. This was followed by a snowballing sampling method as officers in AGIMO and departments conducting the trials identified other departments and agencies involved in online public consultation and citizen engagement.

The research comprised in-depth discussions with senior policy officers, Web masters and communication managers in AGIMO and 11 national government departments and agencies involved in some form of online public consultation. Second, to gain an independent perspective, interviews were conducted with Dr Karen Geiselhart, a former National Office for the Information Economy staffer and co-author of the Democratic Audit of Australia report Electronic Democracy: The Impact of New Communications Technology on Australian Democracy (Chen, Gibson and Geiselhart 2006); Professor Roger Clarke, visiting professor and consultant on information technology strategy and policy at the Australian National University; and Miriam Lyons, director of the Centre for Policy Development, an independent policy 'think tank'. The selection of these interviewees was somewhat subjective, but served to gain an independent perspective from active commentators on online citizen engagement.

The third stage involved comparative analysis with international initiatives and research in online public consultation and citizen engagement using a combination of interviews and literature research. This included discussions with Richard Allan, chair of the UK Power of Information Task Force following the Power of Information review (Mayo and Steinberg 
2007) and again following release of the Task Force's final report in early 2009 (UK Cabinet Office 2009); William Perrin, former policy adviser on online strategy in the Policy Directorate of 10 Downing Street and secretary to the Power of Information Task Force; and Ben Self, technology director of the Democratic National Committee and one of the key people involved in President Obama's online election campaign. As well, the Digital Dialogues Third Phase Report from an independent review of online engagement between central government and citizens in the UK (Miller and Williamson 2008), the UK Power of Information Task Force report (UK Cabinet Office 2009), and research reports from MIT's Deliberatorium experiments in online consultation (Iandoli, Klein and Zolla 2009; Klein 2007) were analysed.

\section{Research Questions}

The research was designed to answer six questions from the 'supply side' of online public consultation: what were the objectives of online consultation; what technologies and forms of online consultation were used; why and how were these selected; what barriers were encountered; how were these addressed or how are they proposed to be addressed; and what experiences and learnings were provided by the online consultation trials. Attitudes and perceptions of public servants involved in operationalising online consultation trials were also evaluated.

\section{Key Findings}

Analysis of the three online consultation trials led to many of the same findings in relation to each trial. Therefore, in a second round of data analysis, interview transcripts and literature such as reports were coded by activity or thematic category which was considered more helpful. This identified findings in 10 main areas.

\section{Planning}

Careful and detailed planning was recommended in the Australian Government Information Management Office (2008) Consulting with Government - Online report and was cited as important by most government officials interviewed and all independent authorities. Specifically, respondents agreed that the first stage of planning should clearly identify target participants and objectives of the consultation, including whether it is designed to function as a formal consultation process or in the more laissez-faire nature of online 'conversation' discussed earlier. The UK Digital Dialogues report found that 'online engagement exercises with clear objectives have fared better than those with undefined goals' (Miller and Williamson 2008, ii). However, data gained from interviews, content analysis of consultation sites, and comparison with international experiences suggest that inadequate planning was undertaken in the Australian federal government's trial online public consultation initiatives.

For example, the decision by the Department of Broadband, Communications and Digital Economy to use a blog as its online public consultation platform was, according to interviews with departmental staff, based on planning workshops conducted in August and September 2008. However, an announcement by the Minister for Finance and Deregulation Lindsay Tanner in July 2008 already committed to a consultation 'blog' (Tanner 2008). While it is possible that departmental planning concurred with Minister Tanner's prior commitment, selection of technology to be used, while important, should be one of the last planning considerations, made after target participants, objectives, privacy issues and resources have been identified, according to online communication specialists.

AGIMO and several departments that have launched online public consultation and citizen engagement initiatives argue that planning should involve three key parties: senior policy 
officers, senior IT/Web technical staff, and communication staff. According to the experiences of AGIMO officers, when initiatives are led by Web managers and IT staff without full involvement of communication/public relations professionals, the results are technically efficient but not user-friendly. When managers in IT or communication develop online consultation initiatives but senior policy officers are not involved and supportive, there is likely to be a lack of resources allocated to manage the site and a lack of linkages to policymaking. The latter is most important. Senior policy maker involvement is essential to ensure that online public consultation initiatives are not tokenism providing little more than cathartic experiences for citizens. Such approaches are widely condemned (Nelkin and Pollak 1979; Fitzpatrick and White 1997) as, in the open collaborative environment of Web 2.0, they are likely to be exposed and result in citizen abandonment of consultation sites.

Given low levels of citizen participation generally in politics, community life and media (Dahlgren 2009, 1; Putnam 2004), marketing and promotion may need to be carried out to make citizens aware of channels available, how to participate, and even to incentivise participation, and this needs to be considered in the planning stages as such activities require resources and involve a lead time. For instance, the UK central government offered $£ 20,000$ in prizes in its 'Show us the way' consultation project after earlier experiences in which relatively low levels of participation were achieved and the MIT Deliberatorium (formerly called the Collaboratorium) uses contests in which teams are asked to competitively develop policy scenarios (Klein et al. 2006, 3).

Forrester Research's six-level Ladder of Participation estimates that only 13 per cent of US adults online are creators, compared with 52 per cent who are 'inactives' and 33 per cent who are 'spectators' (Li 2006). Another industry study commissioned by Cisco Internet Business Solutions Group estimates that up to 90 per cent of internet users are 'lurkers', with only 10 per cent being active participants in interactive environments (Lange et al. 2008, 2), a finding broadly supported in relation to online political engagement by the UK Digital Dialogues report (Miller and Williamson 2008, p. iii). While reading and listening without contributing can comprise a form of engagement - and even an important form of engagement - Michael Schudson's (1998) concept of the monitorial citizen attests to the interest of citizens in civic life, but the inability or unwillingness of many to actively participate. This suggests that engagement and participation need to be defined broadly and that realistic targets for active contribution should be set for online public consultation.

Measuring participation levels, ideally both quantitatively and qualitatively, is one aspect of evaluation which is frequently overlooked or inadequately undertaken in planning online public consultation, according to AGIMO and a number of researchers (Abelson and Gauvin 2006; Rowe and Frewer 2004). Evaluation criteria and methodology need to be established during planning so there is consensus on what constitutes success and so that data can be collected.

\section{Controversial Issues}

A second key finding is that controversial issues can overtake and hijack online public consultation, resulting in much online discussion being 'off topic' and the consultation not achieving its objectives. In all three of the Australian online public consultation trials, a simmering public issue threatened the functioning of the sites and achievement of their stated objectives. Only weeks prior to launch of the Department of Broadband, Communications and Digital Economy consultation blog, the department had announced a proposal to introduce internet filtering which attracted widespread criticism from media and groups such as The Australian Network for Art and Technology (2008) and Electronic Frontiers Australia (2008). This controversial proposal subsumed general discussion of broadband developments 
on the blog. For instance, under a headline stating 'Bloggers pan government's e-democracy bid', the Sydney Morning Herald (11 December 2008) reported: 'Prominent Australian bloggers have lashed the Federal Government over its first attempt at public consultation via a blog, which has already been hijacked by critics of its plan to censor the internet' (Moses 2008, para. 1). Similarly, the National Human Rights Online Consultation was targeted by a long-running campaign to introduce a Bill of Rights in Australia and the Department of Education, Employment and Work Relations online consultation for teachers and educators to discuss early childhood education was launched in the midst of the controversial collapse of the nation's largest childcare provider, ABC Learning Centres.

While it could be seen to be contrary to the objectives of democratic public consultation to attempt to dictate topics and constrain discussion, the potential for vested interests, mobilised 'smart mobs', or the 'usual suspects' among political actors to take and hold the stage needs to be considered.

\section{Timeframe}

Another key challenge in online public consultation identified by AGIMO and emphasised by international research is that online communication occurs in a much faster timeframe than traditional government-citizen communication. Public Service rules and procedures in relation to Ministerial communications prescribe approval procedures that are unwieldy for online communication. A number of Public Servants interviewed express willingness to interact dynamically with citizens online, but are concerned at not being authorised to comment publicly. The need to refer matters to a senior departmental head or even a Minister imposes delays incommensurate with the nature of online consultation. It seems from this research that governments seriously intent on engaging in online public consultation need to implement fast-track approval procedures, authorisation of additional spokespersons on specific topics, and development of pre-prepared responses on a range of questions and topics.

\section{Resources}

Requirements for planning, moderation, IT support, spokespersons who can respond quickly to online questions and discussion, evaluation, and analysis of potentially large volumes of text to identify key themes and areas of consensus have significant resource implications. A key consideration in resourcing is that both outbound and inbound stages need to be addressed. While all departments and agencies studied considered and made some allocation of resources for establishing online consultation sites and for distributing information about the site, little consideration was given in most cases to processing incoming information. If governments implement public consultation with a genuine commitment to listen to and consider citizens' views as is desirable, specific consideration needs to be given to how citizens' contributions will be processed, analysed and articulated into policy-making processes. When listening can involve many thousands of Web posts and possibly e-mails and other communications, dedicated staff are required to acknowledge, categorise, process and respond to public comments, complaints and suggestions.

\section{Culture}

In this research, only two interviewees commented specifically on culture as a key issue and these were independent commentators, not government officials. Karen Geiselhart is sceptical that true e-democracy will emerge from current government initiatives. She argues that entrenched practices and bureaucracy in the administrative echelons of government will stymie attempts to open up public consultation to a wider citizenry (personal communication, 20 August 2008). Nor is the bureaucracy likely to be flexible in the type of input that is accepted, she believes. She says the public service needs to 'loosen up', but believes this will 
require a large cultural shift that most are disinclined to make, preferring instead to cling to a control paradigm of communication and carefully framed and managed consultation.

Roger Clarke says the Australian Public Service views consultation as a constraint and believes that institutional barriers will block any effective extension or widening of public consultation (personal communication, 9 December 2008). In fact, Clarke warns that government departments and agencies may become less accessible to public interest groups and civil society because of online public consultation and see online consultation sites such as blogs as fulfilling their consultation obligations.

Culture is raised as a major finding because, in addition to these minority views by independent commentators, it is cited as a key factor by chair of the UK Power of Information Task Force Richard Allan (2009) and by veteran UK public sector 'e-champion' William Perrin (2009) who believe that changing the culture within the public service will be a prerequisite for effective online public consultation and citizen engagement. However, Allan and Perrin are more optimistic than Australian commentators cited, saying that 'exemplars' such as the highly popular Fix My Street initiative in the UK (www.fixmystreet.com) can be used to inspire and engineer change. In addition, they cite the importance and effectiveness of evangelists to champion expansion of public consultation and citizen engagement.

\section{Design and Navigation}

International studies have revealed government Web interfaces to be a maze of often poorly interconnected sites named and structured in a way that requires an understanding of the workings of government. For instance, the UK Power of Information Task Force review reported the existence of more than 3,000 UK central government Web sites. The Task Force recommended reducing this to 1,000 sites (Mayo and Steinberg 2007).

Studies show that online public consultation and participation initiatives need to offer easily navigable and user-friendly environments. At a macro level, requiring citizens to understand the structure of government and provide their contributions in the correct departmental or topic forum erects a substantial barrier to participation, according to Richard Allan (2008). At a micro level, design should ensure easy-to-follow layout, features for users with disabilities such as a facility to increase font size for the vision-impaired, and consideration of multiple languages.

Online public consultation in relation to the National Human Rights Consultation was found in this research to be poorly designed and difficult to navigate. The consultation initiative, primarily comprised of face-to-face workshops and seminars held around Australia, was extended online from January to 26 June 2009. The consultation was conducted by an independent National Human Rights Consultation Committee appointed by the AttorneyGeneral, not through the Australian Human Rights Commission which also reports to the Attorney-General and is a long-established and well-known organisation.

Many citizens could be expected to go to the Human Rights Commission Web site to find information and participate in consultation. However, clicking a link to 'Consultation Electronic Forum' on the home page of the Australian Human Rights Commission Web site linked to an article written by Fr Frank Brennan, chair of the National Human Rights Consultation Committee, in the independent 'think-tank' blog Open Forum (www.openforum.com.au/NHROC). It was not apparent to visitors that Open Forum was hosting the online consultation. In the Open Forum article, the only link to engage in online consultation was located in the text near the bottom of the page. It linked to 
http://www.humanrightsconsultation.gov.au, a page of introductory information inviting visitors to 'Share your views by participating in an Online Consultation' in which a further link sent visitors to another page of general information also titled 'Share your views' (www.humanrightsconsultation.gov.au/www/nhrcc/nhrcc.nsf/Page/ShareYourViews_Nationa lHumanRightsOnlineConsultation). Here, confusingly, a link to 'National Human Rights Online Consultation' sent site visitors back to Open Forum. It took the researchers up to seven clicks to reach a Web page where a citizen could provide comment on human rights and, on average, the researchers visited three Web sites before locating the online public consultation interface. Upon finally locating the page where online consultation could occur, citizens were confronted with a relatively unwelcoming form requiring extensive personal details as shown in Figure 1.

\section{Figure 1: The National Human Rights Online Consultation Web interface}

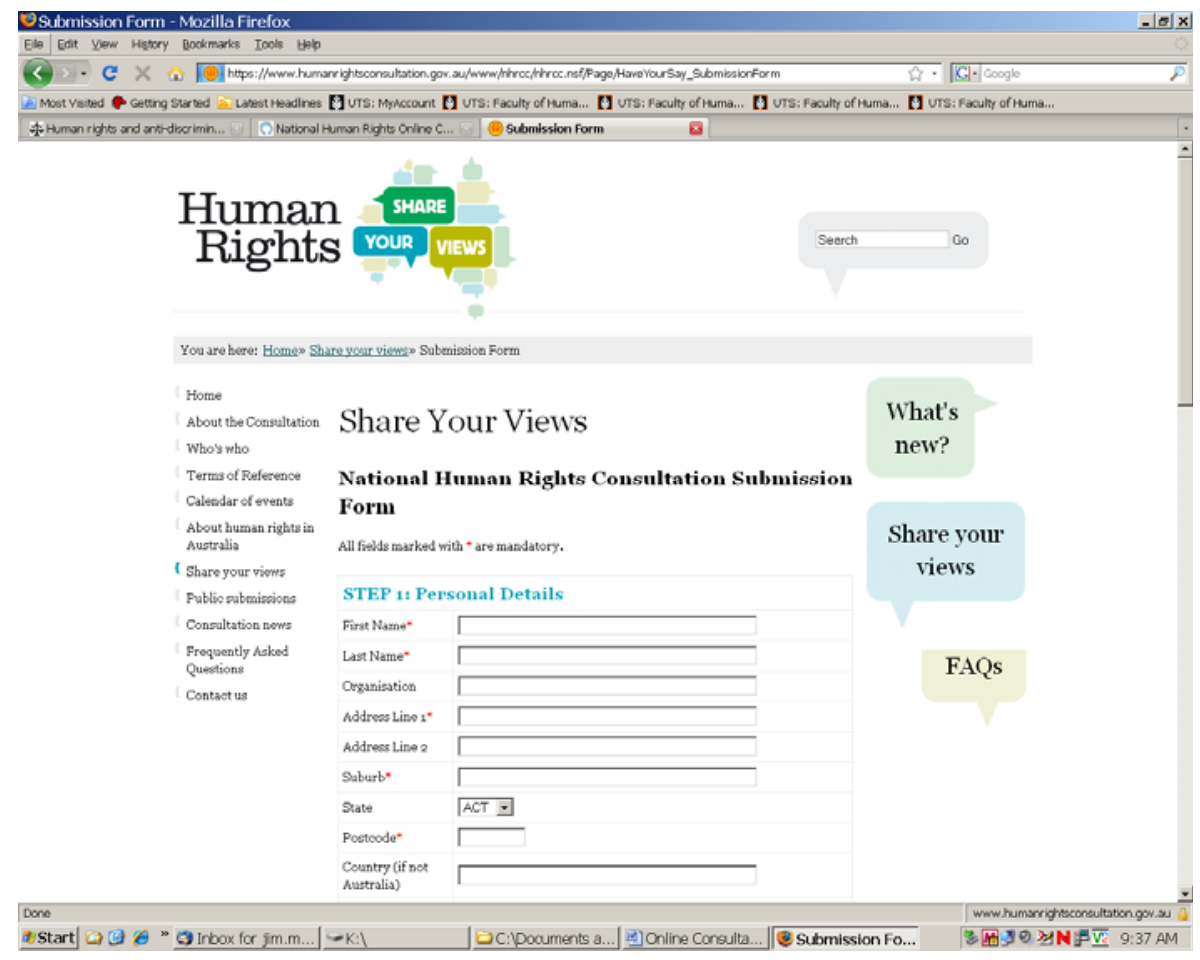

Online specialists and commentators also criticised the presentation of the Department of Broadband, Communications and Digital Economy blog launched by Senator Conroy in relation to design and navigation, such as this comment published in APC magazine:

People expect blogs to have a certain look and feel. They present short updates, have a clean, simple and uncluttered navigation system, and invite reader comments ... Senator Conroy's 'blog' is little more than articles on the department's cumbersome, formally designed website, with the ability for people to post comments underneath them (Warne 2008).

\section{Language}

A further finding of this research closely related to culture and useability is that language can pose a substantial barrier to effective online public consultation and citizen engagement. Melbourne blogging consultant, Darren Rowse, says the Australian government's trial blog looked 'very governmental' and he predicted that it would 'struggle to build a connection with readers'. He says the official look and feel, formal writing style and existence of 'terms of use' and a 'moderation policy' 'killed some of the spontaneity, playfulness and personal nature of blogging' (cited in Moses 2008, paras 7, 11). 
Satire, parody, spoofs and even ridicule have been widely used forms of political expression for centuries (Coleman 2008; Macnamara 2008; Street 2001). Stephen Coleman observes that historically 'democracy ... is rooted in expressive, cathartic, and carnivalesque practices that connect public policy to mundane culture. But the e-citizenship projects we have explored tend to be characterised by an earnest solemnity' $(2008,203)$. This was apparent in the case of the Australian federal government's three online public consultation trials. Coleman adds that 'official strictures about what constitutes respectable (and respect-worthy) political participation have the effect of narrowing the repertoire of political citizenship' to formal, highly structured forms of engagement unsuited to many people today (cited in Earl and Schussman 2008, 73).

\section{Government or Third Party Hosting}

A major consideration for government in undertaking online public consultation and encouraging citizen engagement is whether to host the consultation site or leverage existing online discussion sites. All government officials interviewed strongly favour governmenthosted consultation sites, pointing to issues of privacy, security and moderation to retain some level of control. While formal consultation processes may need to be government hosted given protocols and procedures in relation to submissions, for example, in the broader concept of online citizen engagement proposed there is a strong argument that government should go to the people rather than making people come to it.

Opening up government consultation beyond formal government sites, and even opening up some government information and data to third party applications, is strongly endorsed by the UK Power of Information Task Force. This has both a pragmatic and social equity rationale. Richard Allan cites NetMums as an example of an existing organisation with 500,000 members actively involved in discussing issues of concern and importance to UK mothers. In Australia, major online groups such as GetUp have in excess of 300,000 members and are active in expressing views on various issues.

A second reason for government departments and agencies to participate in public forums hosted by third parties is that discursive practices within government sites inevitably remain bound by a significant imbalance in power relationships which can limit participation levels and the effectiveness of government-hosted and managed online consultation sites.

Stephen Coleman refers to two types of online citizenship as managed e-citizenship and autonomous e-citizenship and concludes that there can be 'conflict between the two faces of e-citizenship' (2008, 192). Coleman says a key policy question for governments is 'are they in favour of merely promoting participation on their own terms or are they prepared to commit to a policy of democratic participation?' (2008, 201-2). As Coleman says, it is not a case of one or the other. Rather democratic societies can benefit from 'a productive convergence between these two models of ... citizenship'.

\section{Sense-making Tools}

Making sense of disparate and initially unconnected and fragmented information and viewpoints contributed in online consultation and citizen engagement represents a substantial challenge for both citizens participating and for government in processing and acting on contributions post-consultation. AGIMO has identified a need for data mining and text analysis tools to process contributions received from citizens participating in online consultation, and is investigating a number of software applications to assist in making sense of the thousands or even millions of words of text that can be received in popular online 
consultation sites. However, sense making in online consultation requires much more than data mining and text analysis tools.

An online experimental research project at the Massachusetts Institute of Technology (MIT) initially called The Collaboratorium (Klein 2007) and renamed The Deliberatorium in 2008 (Iandoli, Klein and Zolla 2009, 70) gives useful insights into the approach and tools required to gain and maintain citizen engagement and for both users and sponsors to effectively participate in large-scale online consultation. In reporting on an online climate change forum, Klein (2007) identifies a number of key requirements for effective online engagement. These include careful design of the rules of interaction; 'seeding' of discussions with 'an initial corpus of policy options and pointers' to stimulate discussion; a 'committed community of contributors and expert judges'; voting systems which provide citizens with simple quick ways of contributing; and tools for collating and assessing well-structured arguments.

Three types of argumentation tools have been identified as important in the MIT Deliberatorium, based on de Moor's and Aakhus' (2006) argumentation support model sharing tools, funnelling tools and argumentation tools. Klein (2007) says that system design should include aids such as articles for users to read to become familiar with issues, ideas and for and against views before participating; 'argument maps' to locate ideas and arguments on a given topic grouped or linked together; and simple tools for users to search, add comments, rate, and vote on articles and ideas, as well as post new articles. Also, Klein says editors or moderators are essential in the process to provide immediate feedback to users such as simple 'thank you' acknowledgements of contributions. The view is supported by experiences from the Obama presidential election campaign in the US. Ben Self says a very small team of specialists processed all online communication with citizens during the 2008 presidential campaign and one of the key strategies that made this possible was the use of 'placeholders' and pre-prepared stock responses that could be mass e-mailed with minimum customisation (personal communication, 16 February 2009).

Table 1 provides a summary of the steps and requirements for both government managers of online consultation sites and participating citizens based on this research as well as findings of the UK Digital Dialogues review (Miller and Williamson 2008), the MIT Deliberatorium and learnings from the 2008 US presidential campaign.

Table 1: Key requirements of government and citizens in online consultation

\begin{tabular}{l|l}
\hline Government Requirements & Citizens Requirements \\
\hline Monitoring (listening) & Background reading (eg. sidebars, links) \\
\hline Stock responses, placeholders & Simple voting and seconding \\
\hline Data/text mining & Editors' summaries \\
\hline Categorising (grouping ideas and arguments) & Categorising (grouping ideas and arguments) \\
\hline Argumentation software & Argumentation software \\
\hline
\end{tabular}

\section{Communities of Practice and Communities of Interest}

While a key finding of this research is that online public consultation can be overwhelmed and hijacked by controversial issues making rational debate difficult if not impossible, an equally important finding is that within particular communities of practice and communities of interest consultation can proceed relatively smoothly and productively. Beyond the three online consultation trials studied, this research found a number of government departments 
and agencies using online public consultation and citizen engagement for specific communities of practice and communities of interest with considerable effectiveness. The Australian Taxation Office, studied closely by Dunleavy et al. (2008) is expanding its use of Web 2.0 tools including blogs and wikis, and in early 2009 created an online community of practice within www.govdex.gov.au for its Large Business Advisory Group. Austrade targets small to medium businesses with a blog and a Facebook presence. The Australian Bureau of Statistics is using blogs and experimenting with other interactive communication tools and supports the 'backstage' concept of making its data available to third party applications.

Arts and cultural organisations are also active in using Web 2.0 use for engaging with particular communities of practice and communities of interest. Noteworthy among those studied are the Australian War Memorial which uses internal and external blogs and has joined The Commons, an international Flickr community supported by around 30 museums, libraries and archive holders internationally, and the Australian Museum where Dr Lynda Kelly has created Musuem 3.0, a Ning-based social network for those interested in the future of cultural institutions (http://museum30.ning.com).

\section{Conclusions - The Quadrivium of Policy, Culture, Resources, Technology}

Findings from this research can be further grouped into four broad areas of management focus. A wide range of findings including the importance of identifying clear objectives and target participants; involvement of senior policy, IT and communication staff; articulation into policy-making processes; timing; evaluation; and key decisions in relation to moderation; acceptable forms of input and language; authorisation of staff to speak publicly; and decisions on government or third party hosting, illustrate the extent and importance of policy in relation to online consultation. Some 70 per cent of the findings of this research relate to policy and planning. Second, major international studies and experiences, as well as the views of independent commentators in Australia, point to the importance of culture and the need for cultural change as well as technological change. It can be argued that these two areas need to be prioritised, as without the necessary policy framework and a supportive culture in place, no amount of resources or technology can make online public consultation effective. With those in place, resources are then required and these include specialist skills which may require investment in training and development, as well as additional staff and financial investment. While technology receives most attention in many discussions of online communication, analysis of research findings into broad disciplinary areas shows that technology is the fourth area for address in this quadrivium.

Political science professor Jeffrey Johnson warns that 'efforts to create e-democracy do not necessarily enhance liberal democratic politics, tending instead toward illiberal politics because of the underlying technological culture of e-democracy' $(2006,85)$. This focus needs to be shifted in the directions indicated by this research. This view is supported by an OECD report, Promise and Problems of E-Democracy, which states: 'the barriers to greater online citizen engagement in policy-making are cultural, organisational and constitutional not technological’ (OECD 2003b, 9).

When decisions are made on technology, a number of limitations of Web platforms and applications used in trial and pioneering online public consultation need to be recognised. Blogs, as well as online forums and even Twitter, can be effective as an open channel for canvassing ideas and topics for discussion (e.g. what issues are concerning people). However, blogs are unsuitably structured to serve as the repository of a large amount of information which others need to access and in which they wish to find specific issues and topics. Roger 
Clarke says bluntly 'blogs are a really dumb idea ... the technology is all wrong ... blogs are dysfunctional' as a public consultation technology (personal communication, 9 December 2008). While blogs can be made more easily navigable using folksonomies such as tag clouds, their reverse chronological linear structure means that content on the same topic contributed by different citizens at different times is fragmented and cannot be reorganised into categories. In this respect, wikis offer a more manageable and easily navigable technology. However, wikis can be complex for citizens unfamiliar with online environments.

Online public consultation projects may require a purpose-designed database to serve as the central content repository, with a number of layers established in the processes of contributing and accessing information from the central repository. These layers include moderation, initial acknowledgement, categorisation and structuring of arguments, and provision of editors' summaries by specialist trained staff. As well, Figure 2 illustrates the importance of background reading available outside of the discussion forum for participants to access prior to making contributions which improves the quality of discussion. Furthermore, it illustrates the importance of building a layer for articulating the main findings from online public consultation and citizen engagement to the policy-making process. Otherwise, widely held views and the best ideas of citizens remain orphaned in some database or Web archive.

Figure 2: A Model of Proposed Key Steps and Stages in Online Public Consultation

\section{Government}

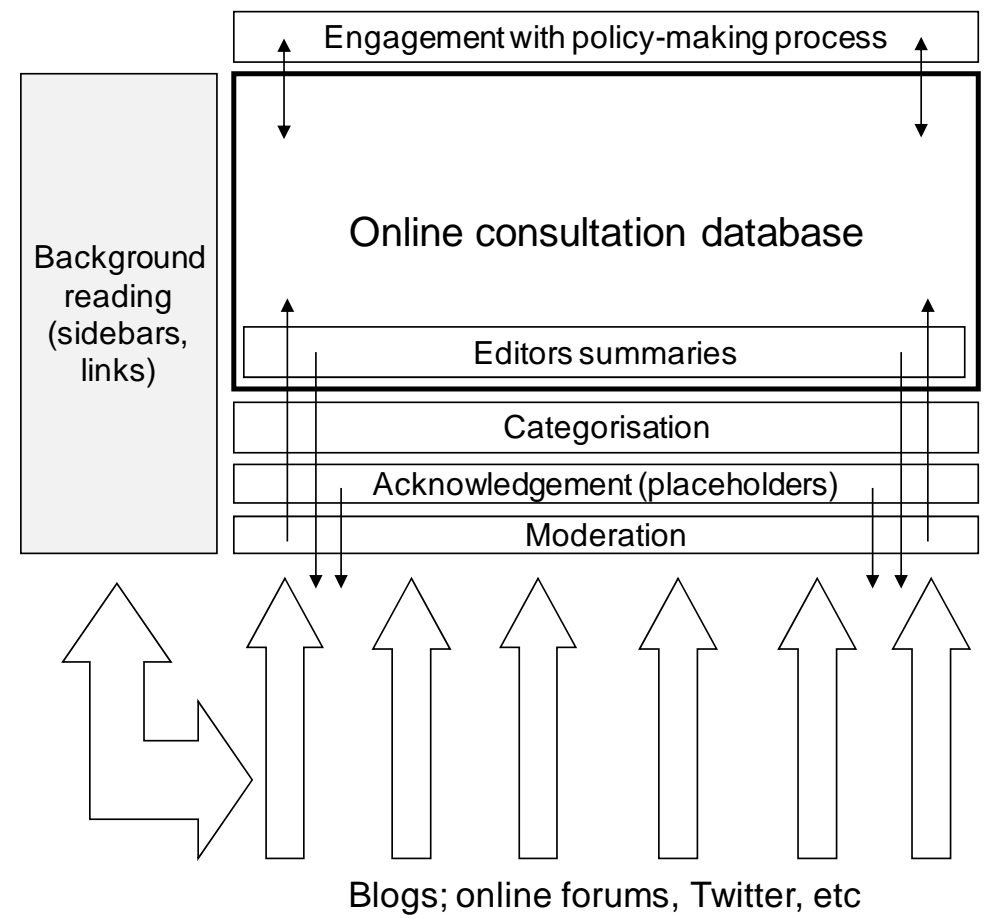

Citizens

Interviews conducted and analysis of the literature indicate that there is no agreed single solution for public consultation. Rather, than a one size fits all approach, careful planning will suggest the most appropriate mix of methods and technologies to meet objectives and the needs of specific participants, and multi-platform approaches to online engagement are likely the most effective (Miller and Williamson 2008, ii). Also, online public consultation and citizen engagement need to be seen as a complement to rather than a replacement for 
traditional forms of consultation. An Australian Communications and Media Authority (2008) report on online participation notes that 2.6 million Australians do not use the internet at home and 13 per cent of all Australians aged 14 years and over have never used the internet.

The trivium of democratic politics remains language (grammar), rhetoric, and argument through the dialectic and much of this will continue to be through traditional political processes and channels. For e-democracy or government 2.0 to succeed and complement these processes, disciplinary focus needs to turn to the quadrivium of policy, culture, resources and technology.

\section{References}

Abelson, J. and F. Gauvin. 2006. Assessing the Impacts of Public Participation: Concepts, Evidence and Policy Implications (Research Report P 06), March. Ottawa, Canada: Canadian Policy Research Networks.

Allan, R. 2008. 'Open government: Future Trends'. Address to forum hosted by Cisco Systems Global Access Partners, 27 June. Sydney.

Allan, R. 2009. Telepresence online forum hosted by Cisco Systems, 26 February. London, Sydney and Canberra.

ASPA [American Society of Public Administration] and UNDPEPA [United Nations Division for Public Economics and Public Administration]. 2002. Benchmarking E-government: A Global Perspective - Accessing the Progress of the UN Member States. Report, May. New York.

AGIMO [Australian Government Information Management Office]. 2008. 'Consulting with Government - Online', June. Canberra. URL:

$<$ http://www.finance.gov.au/publications/consulting-with-government-online/index.html>. Consulted 1 September 2008.

Australian Communications and Media Authority. 2008. Digital Media Literacy. Canberra. URL: <http://www.acma./gov.au/WEB/STANDARD/pc=PC_311474>. Consulted 19 December 2008.

Australian Network for Art and Technology. 2008. 'Clean Feeds on Australian Artists'. News release, 27 October. URL: <http://www.anat.org.au/news_items/105>. Consulted 27 October 2008.

Burgess, S. and J. Houghton. 2006. 'E-government in Australia'. In Comparative Perspectives on Egovernment, eds P. Hernon, R. Cullen and H. Relyea. Lanham, Maryland: Scarecrow Press, 84101.

Chen, P., R. Gibson and K. Geiselhart. 2006. ,Electronic Democracy? The Impact of New Communications Technologies on Australian Democracy'. Report No. 6, Democratic Audit of Australia. Canberra: Australian National University. URL: $<$ http://arts.anu.edu.au/democraticaudit/search_keyw_frm.html>. Consulted 1 November 2008.

Coleman, S. 2008. 'Doing IT for Themselves: Management Versus Autonomy in Youth Ecitizenship’. In Civic Life Online: Learning How Digital Media Can Engage Youth, ed. W. Bennett. Cambridge, MA: MIT Press, 189-206.

Dahlgren, P. 2009. Media and Political Engagement: Citizens, Communication and Democracy. New York: Cambridge University Press.

Department of Finance and Deregulation. 2008. 'E-Democracy Community of Practice'. URL: $<$ http://www.finance.gov.au/e-government/better-practice-and-collaboration/cop/edemocracy.html>. Consulted 1 February 2009.

de Moor, A. and M. Aakhus. 2006). 'Argumentation Support: From Technologies to Tools'. Communications of the ACM 49(3): 93-98.

Dunleavy, P., H. Margetts, S. Bastow and J. Tinkler. 2008. 'Australian e-government in comparative perspective'. Australian Journal of Political Science 43:13-26.

Earl, J. and A. Schussman. 2008. 'Contesting Cultural Control: Youth Culture and Online Petitioning. In Civic Life Online: Learning How Digital Media Can Engage Youth, ed. W. Bennett. Cambridge, MA: MIT Press, 71-95.

Electronic Frontiers Australia. 2008. 'No Internet Censorship for Australia'. URL: $<$ http://nocleanfeed.com/>. Consulted 28 October 2008. 
Fitzpatrick, R. and D. White. 1997. 'Public Participation in the Evaluation of Health Care'. Health and Social Care in the Community 5(1): 3-8.

Flew, T. 2008. New Media: An Introduction. South Melbourne: Oxford University Press.

Flew, T. and J. Wilson. 2008. 'Citizen Journalism and Political Participation: The YouDecide 2007 Project and the 2007 Australian Federal Election. Australian Journal of Communication 35(2): 17-37.

Geiselhart, K. 2004. 'Citizen Engagement: The Next Horizon for Digital Government'. In The Vocal Citizen: Labour Essays, eds D. Glover and G. Patmore. Melbourne: Drummond Publishing.

Gibson, R. and S. Ward. 2008. 'Introduction: E-politics - the Australian Experience'. Australian Journal of Political Science 43: 1-11.

Gibson, R., W. Lusoli and S. Ward. 2008. 'The Australian Public and Politics Online: Reinforcing or Reinventing Representation. Australian Journal of Political Science 43: 111-131.

Goot, M. 2008. 'Is the News on the Internet Different? Leaders, Frontbenchers and Other Candidates in the 2007 Australian Election. Australian Journal of Political Science 43: 99-110.

Habermas, J. 1989. The Structural Transformation of the Public Sphere. Cambridge,UK: Polity.

Habermas, J. 2006. 'Political Communication in Media Society: Does Democracy Still Enjoy an Epistemic Dimension? The Impact of Normative Theory on Empirical Research. Communication Theory 16(4): 411-26.

Held, D. 2006. Models of Democracy. Cambridge: Polity Press.

Hernon, P., R. Cullen and H. Relyea, H. (eds). 2006. Comparative Perspectives on E-government. Lanham, Maryland: Scarecrow Press.

Iandoli, L., M. Klein and G. Zolla. 2009. 'Enabling Online Deliberation and Collective Decision Making through Large-scale Argumentation: A New Approach to the Design of an Internet-based Mass Collaboration Platform. International Journal of Decision Support System Technology 1(1). Hershey, PA: IGI Global.

Johnson, J. 2006. 'The Illiberal Culture of E-democracy. Journal of E-Government 3(4): 85-112.

Kearns, I. 2002. Code Red: Progressive Politics in the Digital Age. London: Institute for Public Policy Research.

Klein, M. 2007. 'The MIT Collaboratorium: Enabling Effective Large-scale Deliberation for Complex Problems (Working Paper 4679-08), 31 December. Cambridge MA: MIT Sloan School of Management. URL: <http://ssrn.com/abstract=1085295>. Consulted 7 November 2008.

Klein, M., T. Malone, J. Sterman, J. and I. Quadir. 2006.'The Climate Collaboratorium: Harnessing Collective Intelligence to Address Climate Change Issues, 22 June. Cambridge MA:

Massachusetts Institute of Technology. URL: <http://cci.mit.edu/collaboratorium.pdf $>$. Consulted 8 November 2008.

Lange, A., Mitchell, S., Stewart-Weeks, M., \& Vila, J. (2008, July). The connected republic and the power of social networks. Cisco Internet Business Solutions Group. URL: <http://www.cisco.com/go.ibsg>. Consulted 1 August 2008.

Li, C. 2006. Social Technographics: Mapping Participation in Activities Forms the Foundation of a Social Strategy. Cambridge MA: Forrester Research.

Macnamara, J. 2008. 'Internet Media and the Public Sphere: The 2007 Australian E-electioneering Experience'. Media International Australia Incorporating Culture \& Policy 129: 7-19.

Mayo, E. and T. Steinberg. 2007. The Power of Information. Report of independent review commissioned by the UK Cabinet Office, June. London. URL: <http://www.cabinetoffice.gov.uk/newsroom/news_releases/2007/070607_power.aspx>. Consulted 29 January 2008.

McAllister, I. 2002. Civic Education and Political Knowledge in Australia (Papers on Parliament 38). Canberra: Department of the Senate.

Miller, L. and A. Williamson. 2008. Digital Dialogues: Third Phase Report August 2007-August 2008. London: Hansard Society.

Moses, A. 2008. 'Bloggers Pan Government's E-democracy Bid'. Sydney Morning Herald online, 11 December. URL: <http://www.smh.com.au/news/technology/bloggers-pan-governmentsedemocracy-bid/2008/12/11/1228585002401.html>. Consulted 29 January 2009.

Nelkin, D. and M. Pollak, M. 1979. 'Public Participation in Technological Decisions: Reality or Grand Illusion?’ Technology Review 81: 55-64. 
OECD [Organisation for Economic Co-operation and Development]. 2003a. 'The E-Government Imperative. E-Government Studies report. Paris.

OECD [Organisation for Economic Co-operation and Development]. 2003b. Promise and Problems of E-democracy: Challenges of Online Citizen Engagement. Paris. URL: <http://www.oecd.org/dataoecd/9/11/35176328.pdf>. Consulted 2 February 2009.

Perrin, W. 2009. Telepresence online forum hosted by Cisco Systems, 26 February. London, Sydney and Canberra.

Putnam, R. ed. 2004. Democracies in Flux: The Evolution of Social Capital in Contemporary Societies. Oxford, UK: Oxford University Press.

Rowe, G. and L. Frewer. 2004. 'Evaluation Public Participation Exercises: A Research Agenda'. Science, Technology, and Human Values 29(4): 512-56.

Schudson, M. 1998. The Good Citizen: A History of American Civic Life. Cambridge, MA: Harvard University Press.

Scoble, R. and S. Israel. 2006. Naked Conversations. Hoboken, NJ: John Wiley \& Sons.

Silcock, R. 2001. ‘What is E-government?’ Parliamentary Affairs 54(1): 88-101.

Smith, A. and L. Rainie. 2008. 'The Internet and the 2008 Election'. Pew Internet \& American Life Project report, 15 June. Washington DC: Pew Research Center. URL:

$<$ http://www.pewinternet.org/PPF/r/252/report_display.asp>. Consulted 6 October 2008.

Street, J. 2001. Mass Media, Politics and Democracy. Basingstoke, Hampshire, UK: Palgrave.

Tanner, L. 2008. Keynote address to e-government forum, CeBIT Australia conference, 21 May. Sydney. URL: <http://www.financeminister.gov.au/speeches/2008/sp_20080521.html>. Consulted 27 May 2008.

Tanner, L. and J. Ludwig. 2009. 'Launch of Government 2.0 Taskforce'. Media statement, 22 June. URL: <http://www.alp.org.au/media/0609/msfindsms220.php>. Consulted 22 June 2009.

UK Cabinet Office. 2009. 'Power of Information Task Force Report', February. URL: $<$.http://www.cabinetoffice.gov.uk/reports/power_of_information.aspx>. Consulted 28 April 2009.

Warne, D. 2008. 'The 10 Sins of Senator Conroy, The Blogger'. APC magazine, 9 December. URL: $<$ http://apcmag.com/the_10_sins_of_senator_conroy.htm>. Consulted 8 June 2009.

Xenos, M. and P. Moy. 2007. 'Direct and Differential Effects of the Internet on Political and Civic Engagement'. Journal of Communication 57(4): 704-18.

\section{Published Reference:}

Macnamara, J. 2010. 'The Quadrivium of Online Public Consultation: Policy, Culture, Resources, Technology’. Australian Journal of Political Science 45(2): 227 - 44.

* Jim Macnamara PhD, MA, FPRIA, FAMI, CPM, FAMEC is Professor of Public Communication at the University of Technology Sydney and Director of the Australian Centre of Public Communication, positions he took up in 2007 after a 30-year professional career spanning journalism, public relations, advertising, and media research. He is the author of 12 books including 'The $21^{\text {st }}$ Century Media (R)evolution: Emergent Communication Practices' published by Peter Lang, New York in 2010. 